\title{
Fragmentation of Methanol Molecules after Core Excitation and Core lonization Studied by Negative-Ion/Positive-Ion Coincidence Experiments
}

\author{
Antti Kivimäki, ${ }^{* 1}$ Christian Stråhlman, ${ }^{2}$ Robert Richter, ${ }^{3}$ and Rami Sankari ${ }^{4}$ \\ ${ }^{1}$ Nano and Molecular Systems Research Unit, University of Oulu, P.O. Box 3000, 90014 Oulu, Finland, \\ and MAX IV Laboratory, Lund University, P.O. Box 118, 22100 Lund, Sweden \\ ${ }^{2}$ Malmö University, 20506 Malmö, Sweden, and \\ MAX IV Laboratory, Lund University, P.O. Box 118, 22100 Lund, Sweden, \\ ${ }^{3}$ Elettra-Sincrotrone Trieste, Area Science Park, 34149 Trieste, Italy \\ ${ }^{4}$ MAX IV Laboratory, Lund University, P.O. Box 118, 22100 Lund, Sweden
}

\begin{abstract}
We have studied the fragmentation of the methanol molecule after core excitation and core ionization by observing coincidences between negative and positive ions. Five different negative ions $-\mathrm{H}^{-}, \mathrm{C}^{-}, \mathrm{CH}^{-}, \mathrm{O}^{-}$, and $\mathrm{OH}^{-}$- were observed at both the $\mathrm{C} 1 \mathrm{~s}$ and $\mathrm{O} 1 \mathrm{~s}$ edges. As negative ion formation occurs after resonant and normal Auger decay of core-hole states, it is necessarily linked with the release of positively charged fragments. Our data show that such fragmentation can happen in many different ways: We found approximately 30 negative-ion/positive-ion/positive-ion coincidence (NIPIPICO) channels. All involve only singly charged positive ions. Fragmentation channels leading to atomic ions are the most probable, but positive molecular ions are also frequently found in the context of anion formation. Coincidence yields as a function of photon energy were determined for the most intense NIPIPICO channels. Adding together the data measured at different photon energies, we could also verify the occurrence of four-ion coincidences, which involved one negative ion $\left(\mathrm{H}^{-}\right.$or $\left.\mathrm{O}^{-}\right)$and three positive ions.
\end{abstract}

\section{INTRODUCTION}

Small molecules usually break into parts after the absorption of an X-ray photon. Such absorption typically involves the transfer of a core electron (such as $\mathrm{C} 1 \mathrm{~s}$ or $\mathrm{O} 1 \mathrm{~s}$ ) to an empty orbital (core excitation) or to the continuum (core ionization). Resulting core-hole states have short lifetimes; they decay on the femtosecond timescale either by electron or X-ray photon emission. More than $99 \%$ of the states with a hole in a $\mathrm{C} 1 \mathrm{~s}, \mathrm{~N}$ 1s or $\mathrm{O}$ 1s shell have been calculated to decay through electron emission. ${ }^{1}$ This decay channel is called (normal) Auger decay in the case of core-ionized states and resonant Auger decay in the case of neutral core-excited states. Both normal and resonant Auger decay most often populate electronic states with two vacancies in valence shells, which usually lead to a fast dissociation of the molecular ion. (The final states of resonant [spectator] Auger decay also include an electron in a molecular or Rydberg orbital, which is empty in the molecular ground state.) Subsequent dissociation mainly produces positive and neutral fragments owing to the positive charge of the molecular ion after normal and resonant Auger decay. However, negative ions (or anions) have also been observed the core edges of several small 
molecules such as $\mathrm{CO},{ }^{2} \mathrm{CO}_{2},{ }^{3} \mathrm{H}_{2} \mathrm{O},{ }^{4} \mathrm{CH}_{3} \mathrm{OH},{ }^{5}$ and $\mathrm{SF}_{6}{ }^{6,7}$ At the core excitations of water, an anion production occurs in at most $0.1 \%$ of all fragmentation events. ${ }^{4}$

Methanol, $\mathrm{CH}_{3} \mathrm{OH}$, the simplest alcohol, consists of a hydroxyl group (OH) attached to a methyl group $\left(\mathrm{CH}_{3}\right)$. Its photofragmentation has been extensively studied with vacuum ultraviolet, soft X-ray, and electron excitation [e.g., ${ }^{5,8-12}$ ]. Eland and Treves-Brown ${ }^{8}$ studied the fragmentation of methanol and its deuterated varieties after photo double ionization by recording photoelectron-photoion-photoion coincidence (PEPIPICO) spectra in the valence region. They concluded that the major reactions involve sequential, not concerted processes, with little hydrogen scrambling, i.e., hydrogen atoms mostly retain their positional identity with respect to the $\mathrm{C}$ or $\mathrm{O}$ atom. Hempelmann et al. ${ }^{9}$ have reported the partial yields of positive ions across both the $\mathrm{C} 1 \mathrm{~s}$ and $\mathrm{O} 1 \mathrm{~s}$ edges of methanol. They also measured some photoion-photoion coincidence yields at the $C$ 1s and $O$ 1s edges. No triple-ion coincidences were detected. Pilling et al. ${ }^{10}$ have reported the relative yields and mean kinetic energies of positive ions, as determined from the PEPIPICO spectra taken around $100 \mathrm{eV}$ photon energy and around the $\mathrm{C} 1 \mathrm{~s}$ edge. The most intense channel was found to be $\mathrm{H}^{+} / \mathrm{CHO}^{+}\left(\mathrm{or} \mathrm{H}^{+} / \mathrm{COH}^{+}\right)$. Some observed coincidence channels involved the $\mathrm{H}_{2}{ }^{+}$and $\mathrm{H}_{3}{ }^{+}$ions that require a rearrangement of nuclei during dissociation. In another study, Pilling et al. ${ }^{11}$ have given the relative intensities of singly charged positive ions at $100 \mathrm{eV}$ photon energy and at three energies around the $\mathrm{C} 1 \mathrm{~s}$ edge. Their time-of-flight mass spectrum taken at $288.3 \mathrm{eV}$ did not reveal any noticeable intensity from doubly charged ions such as $\mathrm{C}^{2+}$ or $\mathrm{O}^{2+}$. However, Stolte et al. ${ }^{5}$ have detected the dications $\mathrm{C}^{2+}$ and $\mathrm{CH}^{2+}$ at the core edges using a $180^{\circ}$ magnetic spectrometer. Additionally, these authors observed the negative ions $\mathrm{H}^{-}, \mathrm{O}^{-}$and $\mathrm{OH}^{-}$around the $\mathrm{C} \mathrm{K}$ edge, but only $\mathrm{O}^{-}$and $\mathrm{H}^{-}$around the $\mathrm{O} \mathrm{K}$ edge. Several fragmentation channels producing anions were suggested, based merely on the conservation of the total charge. Coincidence measurements between negative and positive ions are needed to establish which fragmentation channels have a role in the anion production from methanol. In the present study, we performed such experiments with methanol vapor at the $C 1 \mathrm{~s}$ and $\mathrm{O}$ 1s edges.

We and our colleagues have recently constructed an experimental setup to study molecular fragmentation processes involving both negative and positive ions. ${ }^{13}$ The setup is composed of two ion TOF spectrometers facing each other: one for negative ions, and the other for positive ions. Unwanted electrons are deflected with the aid of a weak magnetic field in order to improve the signal-to-noise ratio in coincidence results. This tandem TOF setup has been used to measure the yields of negativeion/positive-ion and negative-ion/positive-ion/positive-ion coincidences (NIPICO and NIPIPICO, respectively) across the $01 \mathrm{~s}$ edge of water. ${ }^{14}$ It was also used in the investigation of three and four-ion coincidence channels - one of the ions being negative - at the $C 1 \mathrm{~s}$ and $\mathrm{O} 1 \mathrm{~s}$ edges of formic acid. ${ }^{15}$

\section{EXPERIMENTAL}

The experiments on methanol were carried out at the Gas Phase Photoemission beamline at the Elettra storage ring in Trieste, Italy. The beamline has been previously described in detail. ${ }^{16}$ Briefly, it uses an undulator as a light source and a spherical grating monochromator for the selection of photon energy. 
The energy range of the beamline extends from $13.5 \mathrm{eV}$ to about $900 \mathrm{eV}$. A resolving power of $10^{4}$ is achievable in most of this range due to five interchangeable gratings. The radiation is linearly polarized.

The two ion TOF spectrometers were mounted at the so-called magic angle of $54.7^{\circ}$ with respect to the electric vector of the incident synchrotron light. This choice removes the effect of the angular anisotropy parameter, $\beta$, in the intensity distribution of a given dissociation product; ${ }^{17}$ this anisotropy typically changes when measurements are done at different core excitations. While the main components of the instrument have remained the same as in the original setup, ${ }^{13}$ we have managed to improve its performance. The changes in the instrument were discussed in our recent study. ${ }^{15}$ In particular, the cutoff energy of protons could be increased from 2 to $5 \mathrm{eV}$. Pilling et al. ${ }^{10}$ have reported at the $\mathrm{C} 1 \mathrm{~s}$ edge of methanol that some dissociation channels yield $\mathrm{H}^{+}$ions with mean kinetic energies above $5 \mathrm{eV}$, so some of them were still lost. We should therefore be cautious when discussing changes in the corresponding coincidence yields.

Coincidences between negative particles (anions + residual electrons) and positive ions were recorded using a constant extraction field in the interaction region. An external signal generator gave start signals at $10 \mathrm{~Hz}$ frequency to a time-to-digital converter system (ATMD-GPX from ACAM Messelectronic GmBH). All negative particles and positive ions arriving within $80 \mathrm{~ms}$ from the start were saved as STOP1 and STOP2 signals in data arrays, respectively, which allowed $20 \mathrm{~ms}$ for writing the data in a file. The experiments were typically performed by scanning the photon energy across the absorption features of interest and by collecting the coincidence signals at each photon energy for 20 minutes. As a result, these scans became lengthy; the longest one lasted 22 hours, crossing the $C 1 s \rightarrow 3 s$ and $3 p$ excitations with an energy step of $50 \mathrm{meV}$.

Coincidences between negative ions and positive ions were searched for using a custom-made procedure in the data analysis program, Igor $^{\mathrm{TM}}$ (Wavemetrics), after the completion of a measurement. The procedure was written so that signals from the negative-ion detector (STOP1) were considered as effective starts, and those from the positive-ion detector (STOP2) were considered as effective stops. There could be several effective stops for each effective start, and stops arriving before start signals were also considered. The arrival time differences (ATD) between effective stops and starts were written in data arrays which were analyzed by binning nearby arrival time differences (e.g., within 2 ns windows) in histograms. The intensities of the NIPICO channels were obtained by integrating the counts over appropriate ATD ranges in the spectra, while those of the NIPIPICO channels were extracted by counting events in two-dimensional coincidence maps.

The photon energy scales were calibrated according to the literature values of the resonances appearing in the X-ray absorption spectra of methanol. ${ }^{18}$ The photon energy resolution was about $40 \mathrm{meV}$ at the $\mathrm{C}$ $1 \mathrm{~s}$ edge and $80 \mathrm{meV}$ at the $01 \mathrm{~s}$ edge. The ambient pressure in the experimental chamber was about 7.10-

7 mbar during the experiments, but it was estimated to be 10-50 times higher in the interaction region, just above the tip of the needle that was used to introduce sample molecules in the vacuum chamber. The base pressure of the experimental chamber without gas load was $1 \cdot 10^{-7} \mathrm{mbar}$. The photon flux was monitored with a photodiode during the recordings of the coincidence data. The NIPICO and NIPIPICO yields were normalized to the photodiode current. 


\section{RESULTS AND DISCUSSION}

\section{III.1. Identification of Negative lons}

As different coincidence events can have different start signals (such as $\mathrm{O}^{-}, \mathrm{H}^{-}$or electron), the arrivaltime-difference data typically contain several overlapping sub-spectra, and their interpretation is not straightforward. Simulations of flight times of positive and negative ions give the approximate positions of NIPICO peaks. More accurate flight times can be extracted from the recorded coincidence data if some NIPICO peaks can be assigned reliably. It also helps if there are photoelectron/positive-ion coincidence (PEPICO) peaks in the spectra. In the following, we describe the assignment of the NIPICO spectrum of methanol using spectra measured at the $O 1 \mathrm{~s} \rightarrow 4$ s resonance.

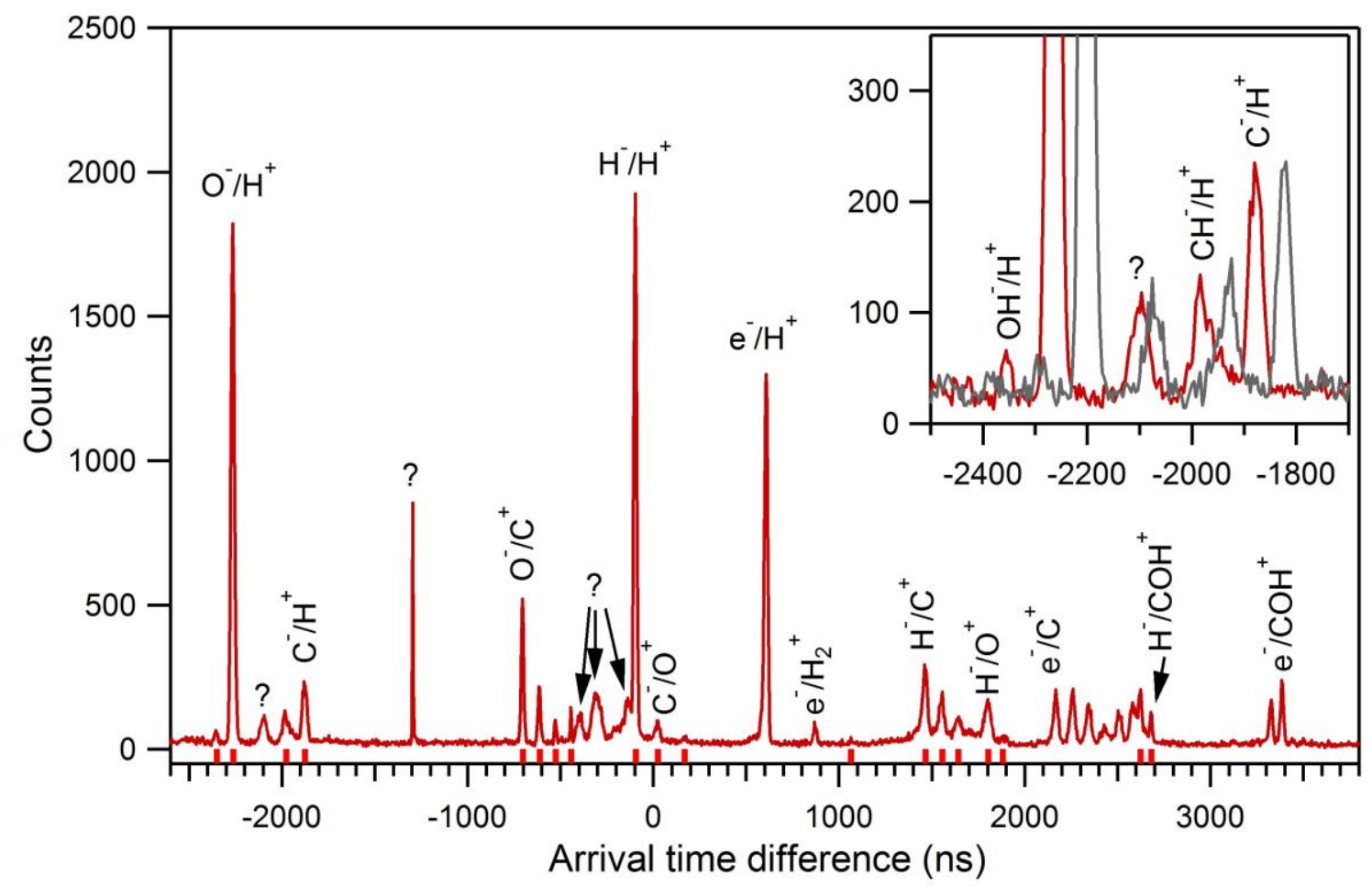

Figure 1. The NIPICO spectrum measured at the $\mathrm{O} 1 \mathrm{~s} \rightarrow 4 \mathrm{~s}$ resonance, photon energy $537.1 \mathrm{eV}$. The insert shows a detail of the TOF spectrum measured using two different drift tube voltages of the negative TOF spectrometer. The bars on the $x$-axis of the main panel indicate the positions of the identified NI/PI coincidence peaks; their assignments are given in Table 1.

The NIPICO spectrum of Figure 1 was measured at the $O 1 \mathrm{~s} \rightarrow 4 \mathrm{~s}$ resonance, which corresponds to the maximum of the photoabsorption cross section at the $\mathrm{O} \mathrm{K}$ edge. ${ }^{18}$ PEPICO peaks, which are due to electrons hitting the negative ion detector despite the magnetic filter, appear at positive arrival time differences (ATDs) because electrons are detected earlier than any positive ions. In contrast, NIPICO peaks can appear both at negative and positive ATDs. A useful trick to help the assignment is to measure a NIPICO spectrum with the drift tube of the negative TOF spectrometer set at a slightly different potential, as has been done in the inset of Figure 1 . This change affected the flight times of negative ions, while 
those of electrons and positive ions remained practically the same. Consequently, NIPICO peaks shifted in the ATD scale, while PEPICO peaks did not. Furthermore, the shifts were larger for heavier negative ions involved in the coincidence event. Based on these arguments, we could conclude, for instance, that the peak around $-2100 \mathrm{~ns}$ in the inset of Figure 1 does not arise from true NI/PI coincidences. The ATD of this peak did change with the change of the drift tube potential but not in the way that is expected for medium-sized negative ions (such as $\mathrm{O}^{-}$and $\mathrm{C}^{-}$) that gave rise to NIPICO peaks in that ATD range. The peak observed at -1984 ns in the red spectrum may have two contributions, one of which originates from $\mathrm{CH}^{-}$ $/ \mathrm{H}^{+}$coincidences. The ATD spectrum also shows some features that we have not been be able to identify; these are labeled with question marks. Their location at negative ATDs (between -100 and -2100 ns) seems to exclude electrons as the source of contamination. Also photons created in the interaction region cannot give rise to these features.

We have given the assignments of some NIPICO and PEPICO peaks in Figure 1. We have determined that the flight times of positive ions in the spectrum of Figure 1 follow the equation $t(m / q)=-23.1 \mathrm{~ns}+\sqrt{(}(\mathrm{m} / q)$ $x 633.1 \mathrm{~ns}$, and those of negative ions follow the equation $\left.\mathrm{t}^{\prime}(\mathrm{m} / \mathrm{q})=-18.7 \mathrm{~ns}+\sqrt{(} \mathrm{m} / \mathrm{q}\right) \times 722.7 \mathrm{~ns}$, whereby we have assumed that electrons give prompt effective starts (this is clearly not true, but it only affects the offsets). According to our simulations, the weak magnetic field used to deflect electrons does not change noticeably the flight times of the negative ions. The expected flight times of possible positive and negative ions are given in Table 1. The positions of the NIPICO peaks can then be obtained by subtracting the flight time of the positive ion from that of the negative ion. The arrival time differences (ATDs) that give good match with observed peak positions are indicated by vertical bars on the $x$-axis of Figure 1 . For instance, the ATD of the $\mathrm{OH}^{-} / \mathrm{H}^{+}$coincidence is expected to be $610 \mathrm{~ns}-2961 \mathrm{~ns}=-2351 \mathrm{~ns}$, which differs by $5 \mathrm{~ns}$ from the measured position of the leftmost distinct peak in the spectrum of Figure 1 (see also the inset).

Table 1. The expected flight times of some possible positive and negative ions as well as the calculated arrival time differences (ATDs) of the observed negative-ion/positive-ion coincidence peaks.

\begin{tabular}{llllll} 
Positive ion & Flight time (ns) & Negative ion & Flight time (ns) & NIPICO & ATD (ns) \\
\hline $\mathrm{H}^{+}$ & 610 & $\mathrm{H}^{-}$ & 704 & $\mathrm{OH}^{-} / \mathrm{H}^{+}$ & -2351 \\
$\mathrm{H}_{2}{ }^{+}$ & 872 & $\mathrm{H}_{2}^{-}$ & 1003 & $\mathrm{O}^{-} / \mathrm{H}^{+}$ & -2262 \\
$\mathrm{H}_{3}{ }^{+}$ & 1073 & $\mathrm{H}^{-}$ & 1233 & $\mathrm{CH}^{-} / \mathrm{H}^{+}$ & -1977 \\
$\mathrm{C}^{2+}$ & 1528 & $\mathrm{C}^{-}$ & 2485 & $\mathrm{C}^{-} / \mathrm{H}^{+}$ & -1875 \\
$\mathrm{CH}^{2+}$ & 1591 & $\mathrm{CH}^{-}$ & 2587 & $\mathrm{O}^{-} / \mathrm{C}^{+}$ & -702 \\
$\mathrm{CH}_{2}{ }^{2+}$ & 1652 & $\mathrm{CH}_{2}{ }^{-}$ & 2685 & $\mathrm{O}^{-} / \mathrm{CH}^{+}$ & -612 \\
$\mathrm{CH}_{3}{ }^{2+}$ & 1711 & $\mathrm{CH}^{-}$ & 2780 & $\mathrm{O}^{-} / \mathrm{CH}^{+}$ & -526 \\
$\mathrm{O}^{2+}$ & 1768 & $\mathrm{O}^{-}$ & 2872 & $\mathrm{O}^{-} / \mathrm{CH}^{+}$ & -443 \\
$\mathrm{OH}^{2+}$ & 1823 & $\mathrm{OH}^{-}$ & 2961 & $\mathrm{H}^{-} / \mathrm{H}^{+}$ & -94 \\
$\mathrm{C}^{+}$ & 2170 & $\mathrm{H}_{2} \mathrm{O}^{-}$ & 3047 & $\mathrm{C}^{-} / \mathrm{O}^{+}$ & 25 \\
$\mathrm{CH}^{+}$ & 2260 & $\mathrm{CO}^{-}$ & 3805 & $\mathrm{H}^{-} / \mathrm{H}^{+}$ & 168 \\
$\mathrm{CH}^{+}$ & 2346 & $\mathrm{CHO}^{+}$ & 3873 & $\mathrm{H}^{-} / \mathrm{O}^{2+}$ & 1064 \\
$\mathrm{CH}_{3}{ }^{+}$ & 2429 & $\mathrm{CH}_{2} \mathrm{O}^{-}$ & 3940 & $\mathrm{H}^{-} / \mathrm{C}^{+}$ & 1466 \\
$\mathrm{O}^{+}$ & 2509 & $\mathrm{CH}_{3} \mathrm{O}^{-}$ & 4005 & $\mathrm{H}^{-} / \mathrm{CH}^{+}$ & 1556 \\
$\mathrm{OH}^{+}$ & 2587 & $\mathrm{CH}_{3} \mathrm{OH}^{-}$ & 4069 & $\mathrm{H}^{-} / \mathrm{CH}^{+}$ & 1642 \\
$\mathrm{H}_{2} \mathrm{O}^{+}$ & 2663 & & & $\mathrm{H}^{-} / \mathrm{O}^{+}$ & 1805 \\
$\mathrm{CO}^{+}$ & 3327 & & & $\mathrm{H}^{-} / \mathrm{OH}^{+}$ & 1883 \\
$\mathrm{CHO}^{+}$ & 3386 & & & $\mathrm{H}^{-} / \mathrm{CO}^{+}$ & 2623 \\
\hline
\end{tabular}




\begin{tabular}{llll}
\hline $\mathrm{CH}_{2} \mathrm{O}^{+}$ & 3445 & $\mathrm{H}^{-} / \mathrm{CHO}^{+}$ & 2682 \\
$\mathrm{CH}_{3} \mathrm{O}^{+}$ & 3502 & & \\
$\mathrm{CH}_{3} \mathrm{OH}^{+}$ & 3558 & & \\
\hline
\end{tabular}

\section{III.2. Possible Pathways Leading to Anion Production}

The stored array data can be used to extract coincidences between negative ions and two (or more) positive ions. As the final states of resonant Auger decay typically have the charge of +1 , the detection of a negative ion implies that other fragments should have the total charge +2 , which can appear either as two singly charged cations or as a single dication. We can present these general dissociation pathways for a hypothetic three-atomic molecule $A B C$ :

$\mathrm{ABC}+\mathrm{h} v \rightarrow \mathrm{ABC}^{* *}$ (core excitation) $\rightarrow \mathrm{ABC}^{+}+\mathrm{e}^{-}$(resonant Auger) $\rightarrow$

$$
\begin{aligned}
& A^{-}+B^{+}+C^{+} \text {or } \\
& A^{-}+B C^{2+} \text { or (negative ion formation) } \\
& A^{-}+B^{2+}+C
\end{aligned}
$$

The contribution of doubly charged positive ions should appear in the NIPICO spectra such as those in Figure 1 . We observe only one tiny peak from such processes: $\mathrm{H}^{-} / \mathrm{O}^{2+}$ at $1064 \mathrm{~ns}$. Clearly, this dissociation pathway is very weak. Additionally, part of its intensity could originate from the dissociation of doubly charged molecular ions (see Section III.6). In contrast, measured data reveal plenty of NIPIPI coincidences, evidencing that charge distribution among many particles is preferred.

So-called ultrafast dissociation has been observed upon core excitation of some small molecules. ${ }^{19}$ This relaxation channel implies that a core-excited molecule breaks into a neutral core-excited fragment and another neutral fragment before the core hole decays electronically. There is experimental evidence that core-excited methanol can dissociate to $\mathrm{CH}_{3} \mathrm{O} * *+\mathrm{H}$ at the first resonance of the oxygen edge, ${ }^{20}$ where $* *$ indicates the core-excited fragment that subsequently undergoes resonant Auger decay. A priori, it appears that the dissociation of the resulting excited final states of $\mathrm{CH}_{3} \mathrm{O}^{+*}$ could lead to negative ion production equally well as the dissociation of the $\mathrm{CH}_{3} \mathrm{OH}^{+*}$ ions (without ultrafast dissociation).

In principle, it is possible that NIPICO events could result from soft X-ray emission decay of core-hole states, but we have not seen conclusive evidence for this pathway in our studies so far. Only the $\mathrm{H}^{-} / \mathrm{H}^{+}$ yield above the $01 \mathrm{~s}$ IP in water may have appreciably been affected by radiative decay, ${ }^{14}$ in that case, from core-ionized molecules.

\section{III.3. Negative-Ion/Positive-Ion/Positive-Ion Coincidence Maps}

Figure 2 shows selected parts of coincidence maps, where two positive ions have been observed together with the negative ions of intermediate masses $\mathrm{C}^{-}, \mathrm{CH}^{-}, \mathrm{O}^{-}$and $\mathrm{OH}^{-}$. Figure 3 shows some NIPIPICO maps for the negative ion $\mathrm{H}^{-}$. The measurements were performed at the maximum of the $\mathrm{C} 1 \mathrm{~s} \rightarrow 3 p$ resonance. In the figures, the $x$-axis gives the ATD of the first positive ion and the $y$-axis gives the ATD of the second 
positive ion, both referenced to the detection of the same negative ion. We can use the derived flight times of the ions from Table 1 to calculate where NIPIPI coincidences should occur. This has been indicated for some weaker channels with red circles, with the center at the expected position and a radius of $25 \mathrm{~ns}$.

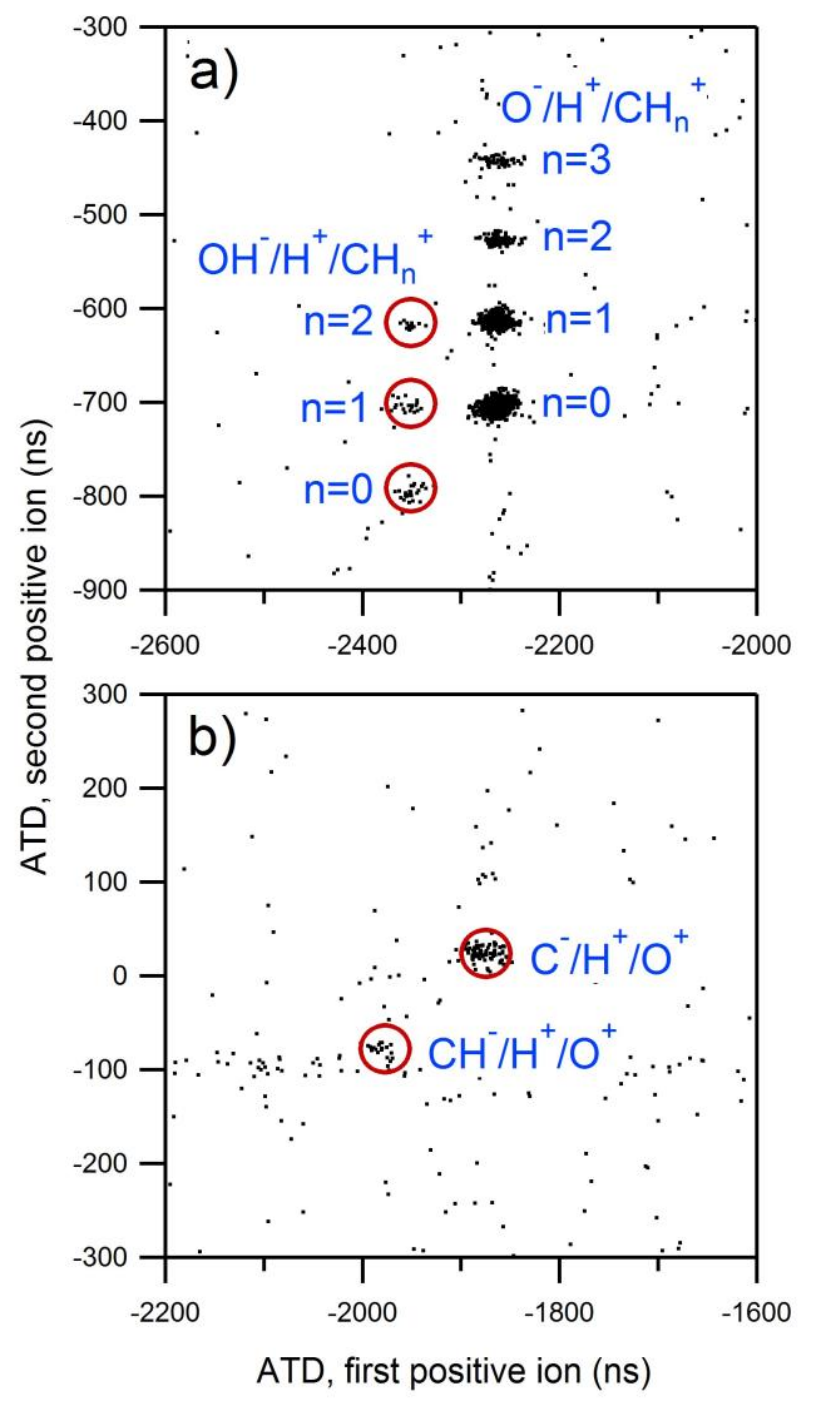

Figure 2. Examples of NIPIPI coincidence maps with $\mathrm{NI}=\mathrm{C}^{-}, \mathrm{CH}^{-}, \mathrm{O}^{-}$and $\mathrm{OH}^{-}$measured at the $\mathrm{C}$ is $\rightarrow 3 p$ resonance of methanol. Red circles show the positions of weaker channels as calculated from the flight times of different ions (Table 1). ATD = Arrival time difference. The measuring time was $60 \mathrm{~min}$. 

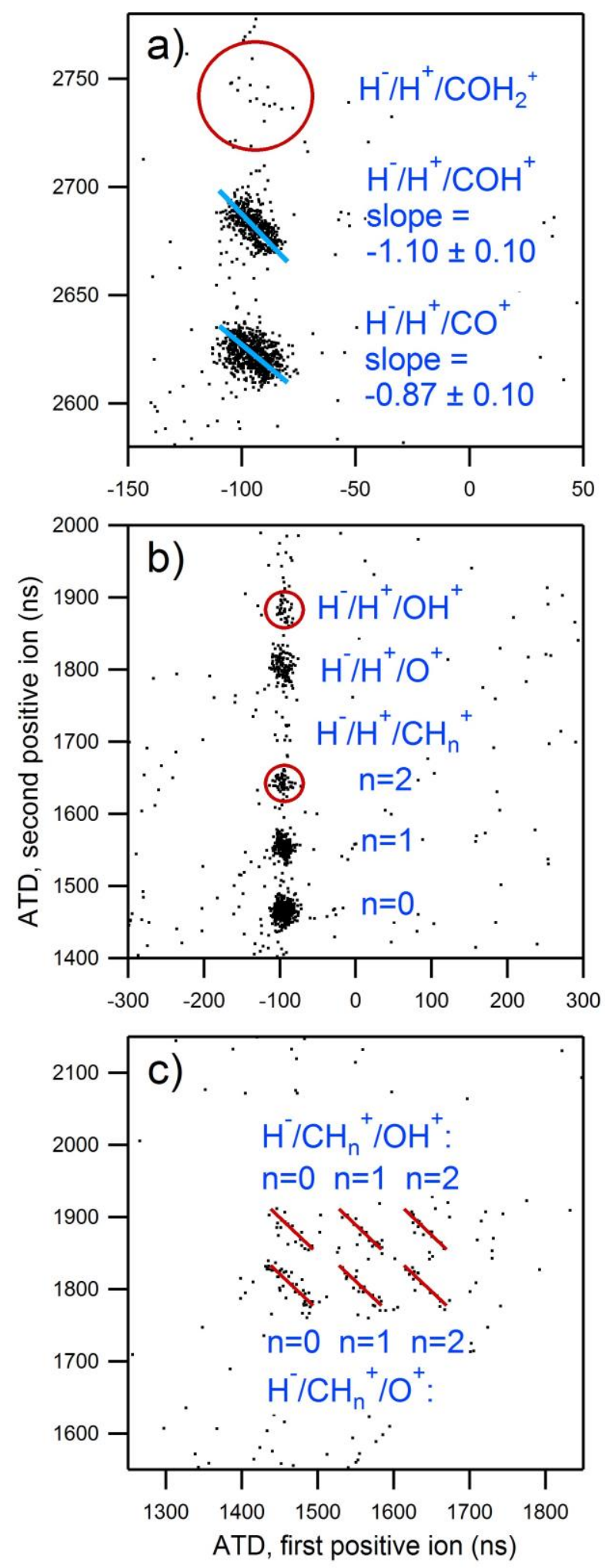

Figure 3. Examples of NIPIPI coincidence maps for $\mathrm{NI}=\mathrm{H}^{-}$measured at the $\mathrm{C} 1 \mathrm{~s} \rightarrow 3 p$ resonance of methanol. Red circles and segments show the positions of weaker channels as calculated from the flight 
times of different lons (Table 1), while light-blue segments in panel (a) show fits to the coincidence data. ATD $=$ Arrival time difference. The measuring time was $60 \mathrm{~min}$.

In Figure 3c, the coincidence tracks appear to form diagonal rectangles or segments. They are highlighted by drawing lines with a slope of -1 around the calculated center position of each coincidence pattern. The lines are not fitted to the data points, but they seem to agree rather well with their distributions. In the dissociation of doubly charged ions, the slope of -1 normally implies the breaking into two singly charged fragments. ${ }^{21}$ In the present case, we interpret this so that the resonant Auger decay produces $\mathrm{CH}_{3} \mathrm{OH}^{+}$, which dissociates to $\mathrm{H}^{-}+\mathrm{CH}_{2} \mathrm{OH}^{2+}$, and is followed by the second-step dissociation, for instance, $\mathrm{CH}_{2} \mathrm{OH}^{2+}$ $\rightarrow \mathrm{CH}_{2}{ }^{+}+\mathrm{OH}^{+}$. If the flight times of the two fragments match the predictions, the doubly charged ion should dissociate very rapidly (very rapidly here could mean up to a few ns) still near the formation point; otherwise, it would be accelerated by the fields. This must be true for all multiple coincidences that can be assigned based on flight times. In principle, if the dissociation of $\mathrm{CH}_{2} \mathrm{OH}^{2+}$ is also sequential (but fast), making first $\mathrm{CHOH}^{2+}+\mathrm{H}$ and fragmenting then further via $\mathrm{CHOH}^{2+} \rightarrow \mathrm{CH}^{+}+\mathrm{OH}^{+}$, the slope should still be 1. Most of the coincidence islands in Figure $3 \mathrm{c}$ do not contain all the atoms of the complete molecule. The loss of a light fragment is generally expected to change the slope, but - as far as we can tell - the changes are not big. The observation of the $\mathrm{H}^{-} / \mathrm{CH}_{n}{ }^{+} / \mathrm{OH}^{+}(\mathrm{n}=0-2)$ channels implies that $\mathrm{H}^{-}$originates from the $\mathrm{CH}_{3}$ group.

The $\mathrm{H}^{-} / \mathrm{H}^{+} / \mathrm{COH}_{n}{ }^{+}(\mathrm{n}=0,1)$ coincidence events in Figure 3a seem to be aligned nearly diagonally. The fits of lines to the data points gave the slopes of $-1.10( \pm 0.10)$ and $-0.87( \pm 0.10)$ for the $\mathrm{H}^{-} / \mathrm{H}^{+} / \mathrm{COH}^{+}$and $\mathrm{H}^{-} / \mathrm{H}^{+} / \mathrm{CO}^{+}$ channels, respectively. Referring to the discussion above, the deviation of the slopes from -1 , if real, would indicate that the two positive ions are not produced at the same time. This conlusion does not tell when $\mathrm{H}^{-}$is created, but we believe this to happen in the first-step dissociation because hydrogen atoms are the outer ones in methanol and an electron typically occupies a diffuse Rydberg orbital after resonant Auger decay. A possible sequence of events is then that, following resonant Auger decay, a $\mathrm{H}^{-}$ion first escapes from the singly charged parent molecule and the resulting doubly charged parent molecule dissociates into two singly charged fragments, one of which dissociates further, with some delay, to ionic and neutral fragments. As an example, a possible dissociation pathway could be $\mathrm{CH}_{3} \mathrm{OH}^{+} \rightarrow \mathrm{CH}_{2} \mathrm{OH}^{2+}+\mathrm{H}^{-} \rightarrow \mathrm{CHOH}^{+}+$ $\mathrm{H}^{+}+\mathrm{H}^{-} \rightarrow \mathrm{COH}^{+}+\mathrm{H}+\mathrm{H}^{+}+\mathrm{H}^{-}$. Eland has analyzed peak shapes in PEPIPICO experiments resulting from the dissociation of doubly charged ions. ${ }^{21} \mathrm{He}$ presented that the peak shapes with slopes differing from -1 can arise when secondary fragmentation occurs with a delay. Our experiments are clearly different, but they may also involve doubly charged ions as intermediate stages.

The most intense NIPIPICO channels at the $\mathrm{C} 1 \mathrm{~s} \rightarrow 3 p$ resonance are $\mathrm{O}^{-} / \mathrm{H}^{+} / \mathrm{CH}_{n}{ }^{+}(\mathrm{n}=0-3), \mathrm{H}^{-} / \mathrm{H}^{+} / \mathrm{CH}_{n}{ }^{+}(\mathrm{n}=0$ 2) and $\mathrm{H}^{-} / \mathrm{H}^{+} / \mathrm{COH}_{n}{ }^{+}(n=0,1)$. In each series, the intensity decreases when $n$ increases. Thus, negative ion production preferably leads to the complete fragmentation of the molecule. Nevertheless, we also observed dissociation reactions where all atoms were included in the fragments detected $-\mathrm{CH}_{3} \mathrm{OH}^{+} \rightarrow \mathrm{O}^{-}$ $+\mathrm{H}^{+}+\mathrm{CH}_{3}{ }^{+}, \mathrm{CH}_{3} \mathrm{OH}^{+} \rightarrow \mathrm{OH}^{-}+\mathrm{H}^{+}+\mathrm{CH}_{2}{ }^{+}$and $\mathrm{CH}_{3} \mathrm{OH}^{+} \rightarrow \mathrm{H}^{-}+\mathrm{H}^{+}+\mathrm{COH}_{2}{ }^{+}$- and which also involved polyatomic positive fragments. Another weak channel $\mathrm{H}^{-} / \mathrm{H}_{2}{ }^{+} / \mathrm{COH}^{+}$(not shown in Figure 3, but visible in Table of Contents figure) also detects all constituent atoms. It is tempting to interpret this channel so that the methyl group would give rise to both a $\mathrm{H}^{-}$and molecular $\mathrm{H}_{2}{ }^{+}$, but similar coincidence measurements of the partially deuterated molecule $\mathrm{CH}_{3} \mathrm{OD}$ are required to confirm this hypothesis. On the other hand, we do 
not observe the $\mathrm{H}^{-} / \mathrm{CH}_{3}{ }^{+} / \mathrm{O}^{+}$channel, but we do see $\mathrm{H}^{-} / \mathrm{CH}_{2}{ }^{+} / \mathrm{OH}^{+}$. This is an indication that $\mathrm{H}^{-}$can be released from the methyl group.

NIPIPICO channels involving $\mathrm{C}^{-}$and $\mathrm{CH}^{-}$ions are weak. Nevertheless, triple-coincidence measurements confirm that both these anions are produced at the $\mathrm{C} 1 \mathrm{~s}$ and $\mathrm{O} 1 \mathrm{~s}$ excitations. We have not shown all the observed NIPIPICO channels in Figures 2 and 3. Additionally, we detected three $\mathrm{NI} / \mathrm{H}^{+} / \mathrm{H}^{+}$channels with $\mathrm{NI}=\mathrm{H}^{-}, \mathrm{C}^{-}$and $\mathrm{O}^{-}$and a rather interesting $\mathrm{H}^{-} / \mathrm{H}^{+} / \mathrm{H}_{2}{ }^{+}$channel, where all the hydrogen atoms of methanol are involved in ion formation, but $\mathrm{C}$ and $\mathrm{O}$ are not. The intensities of the NIPIPICO channels, which comprise the detection of two protons, are underestimated in our experiments because of the dead time of the MCP detector. The total number of different NIPIPICO channels observed at the $C 1 s \rightarrow 3 p$ resonance in the measurement of 60 minutes was at least 29. We expect that a few more channels would have shown up, particularly involving the negative ions $\mathrm{C}^{-}$and $\mathrm{CH}^{-}$, if the measuring time had been even longer. None of the contamination peaks present in the NIPICO spectra of Figure 1 gave rise to groups of dots in the NIPIPICO maps.

\section{III.4. Negative-ion/Positive-ion Coincidence Yields}

If anion formation occurs after resonant and normal Auger decay, at least two positive ions should be created as co-products. However, we observe clearly more negative-ion/positive-ion coincidences (NIPICO) than negative-ion/positive-ion/positive-ion coincidences (NIPIPICO). Our interpretation is that a large majority of negative-ion/positive-ion coincidences (NIPICO) originate from events where the second positive ion was created but not detected. This can be easily accounted for by instrumental effects. Positive ions pass through three meshes before detection. Assuming 90\% transmission for each and a detection efficiency of $50 \%$ in the MCP detector, the probability of coincidence detection drops very fast with the ion number, even without systematic losses.

In general, NIPICO channels as a function of photon energy, which we call yields, receive intensity from different NIPIPICO channels whose relative weights may vary at different core excitations. For instance, the intensity of the $\mathrm{O}^{\%} / \mathrm{H}^{+}$channel contains contributions from the NIPIPICO channels $\mathrm{O}^{\%} / \mathrm{H}^{+} / \mathrm{PI}$, where $\mathrm{PI} 2=\mathrm{H}^{+}, \mathrm{C}^{+}, \mathrm{CH}^{+}, \mathrm{CH}_{2}{ }^{+}$, and $\mathrm{CH}_{3}{ }^{+}$(see Table 1). Nevertheless, NIPICO yields can show approximately how the abundances of different anions vary as a function of photon energy. In Figure 4, we show the NIPICO yields for $\mathrm{PI}=\mathrm{H}^{+}$channels at both the $\mathrm{C} 1 \mathrm{~s}$ and $\mathrm{O}$ 1s edges; the proton being the only positive fragment that was observed with all five different anions. We should not draw conclusions on small changes in the relative NIPICO intensities as a function of photon energy because some fast $\mathrm{H}^{+}$were likely lost in the experiment (see Experimental section) and because NIPICO spectra contain some spurious intensity which became stronger above the core IPs.

At the $\mathrm{C}$ 1s edge, the $\mathrm{H}^{-} / \mathrm{H}^{+}$channel is the most intense NIPICO channel. In comparison to TIY, its yield is somewhat suppressed at the $\mathrm{C} 1 \mathrm{~s} \rightarrow 3 \mathrm{~s}$ resonance and the related vibrational structure and again at the C 1s threshold. The second most intense channel is $\mathrm{O}^{\circ} / \mathrm{H}^{+}$, whose yield follows TIY quite well until the photon energy of $291.5 \mathrm{eV}$, after which it becomes slightly enhanced; this is the region of high Rydberg excitations. The intensities of the other $\mathrm{NI} / \mathrm{H}^{+}$channels are in the order of $\mathrm{NI}=\mathrm{C}^{-}, \mathrm{CH}^{-}$and $\mathrm{OH}^{-}$. The 
increasing intensity above the $\mathrm{C} 1 \mathrm{~s} \mathrm{IP}$ in the $\mathrm{C}^{-} / \mathrm{H}^{+}$and $\mathrm{CH}^{-} / \mathrm{H}^{+}$channels is most likely not real but rather due to contaminating intensity that increased when the core IP was crossed (see also below). Stolte et al. ${ }^{5}$ measured the yield of $\mathrm{OH}^{-}$ions at the $\mathrm{C} 1 \mathrm{~s}$ edge. They found that it had the highest intensity at the first resonance ( $\mathrm{C} 1 \mathrm{~s} \rightarrow 3 \mathrm{~s}$ ). We observed $\mathrm{OH}^{-}$only in coincidence with the $\mathrm{H}^{+}$ion, so the $\mathrm{OH}^{-} / \mathrm{H}^{+}$yield in Figure 3 is comparable to the $\mathrm{OH}^{-}$partial ion yield shown in Ref. 5. Keeping the TIY as a reference, the relative intensity of the $\mathrm{OH}^{-} / \mathrm{H}^{+}$yield is slightly higher at the $\mathrm{C} 1 \mathrm{~s} \rightarrow 3 \mathrm{~s}$ resonance than at the $\mathrm{C} 1 \mathrm{~s} \rightarrow 3 \mathrm{p}$ resonance, but the intensity change is not nearly as large as was observed in Stolte et al.'s study. ${ }^{5}$
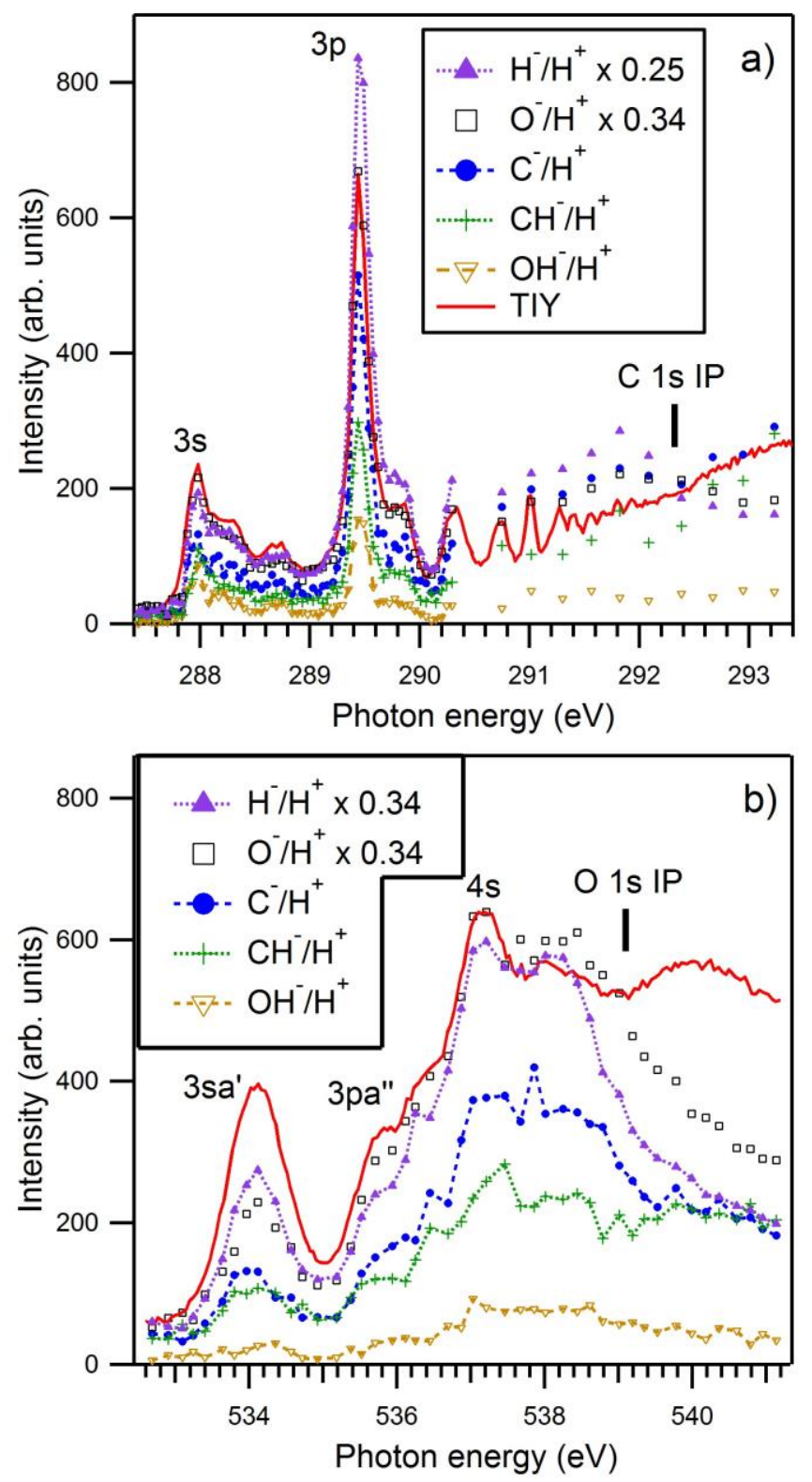

Figure 4. The intensities of the NIPICO channels with $\mathrm{PI}=\mathrm{H}^{+}$at (a) the $\mathrm{C} 1 \mathrm{~s}$ edge and (b) $\mathrm{O}$ 1s edge. The total ion yield (TIY) has been scaled to have the same amplitude as the $\mathrm{O}^{-} / \mathrm{H}^{+}$channel. The yields of the $\mathrm{O}^{-} / \mathrm{H}^{+}$ 
and $\mathrm{H}^{-} / \mathrm{H}^{+}$have been scaled as indicated on the graph in order to better show the behaviors of the weaker NIPICO channels. The assignments of the resonances and the ionization potentials are from Ref. 18.

At the $\mathrm{O} 1 \mathrm{~s}$ edge, the $\mathrm{H}^{-} / \mathrm{H}^{+}$and $\mathrm{O}^{-} / \mathrm{H}^{+}$channels have similar intensities below the $\mathrm{O} 1 \mathrm{~s} \mathrm{IP}$. The ejection of $\mathrm{O}^{-}$thus becomes more likely, in relative terms, when the core excitation originates from the $\mathrm{O}$ atom instead of the $\mathrm{C}$ atom. Above the $\mathrm{O} 1 \mathrm{~s}$ threshold, the intensity of the $\mathrm{O}^{-} / \mathrm{H}^{+}$channel decreases more slowly than that of the $\mathrm{H}^{-} / \mathrm{H}^{+}$. The decreasing tendency could be due to recapture processes to which a similar behavior in the $\mathrm{O}^{-}$yield was attributed above the core edges in the $\mathrm{CO}$ molecule. ${ }^{22}$ We have also extracted the coincidence yields of $\mathrm{C}^{-}, \mathrm{CH}^{-}$and $\mathrm{OH}^{-}$ions together with $\mathrm{H}^{+}$. None of these anions were detected at the $\mathrm{O} 1 \mathrm{~s}$ edge in the non-coincidence experiments of Stolte et al. ${ }^{5}$ The first resonance, $\mathrm{O} 1 \mathrm{~s} \rightarrow 3 \mathrm{sa}^{\prime}$, ${ }^{18}$ appears suppressed in all the NIPICO yields in Figure 4 when compared to the TIY. This excitation has been calculated to possess a considerable $(\mathrm{O}-\mathrm{H}) \sigma^{*}$ character. ${ }^{23}$ Our observations could indicate that fewer anions are produced at the $\mathrm{O} 1 \mathrm{~s} \rightarrow 3 \mathrm{sa}^{\prime}$ ( or $\mathrm{O} 1 \mathrm{~s} \rightarrow(\mathrm{O}-\mathrm{H}) \sigma^{*}$ ) excitation, but the observation could also be explained, at least in principle, by the ejection of more energetic protons at this dissociative resonance.

\section{III.5. Negative-ion/Positive-ion/Positive-ion Coincidence Yields}

NIPIPICO yields are more informative than NIPICO yields because the detection of the second positive ion characterizes the dissociation channels more accurately. In addition, the intensities of the NIPIPICO events can be determined more reliably since any contamination processes in the ATD spectra (see Fig. 1) are likely avoided because they hardly involve the coincidence detection of three ions. The NIPIPICO intensities were obtained by counting events in the appropriate regions of coincidence maps such as those shown in Figures 2 and 3. The same areas were used for all photon energies of the scans. The obtained numbers of events were normalized to the photon flux so that the maximum number of the curve was maintained. The results are shown in Figures 5 and 6 . Thus, we observed at maximum $\sim 190$ events in the $\mathrm{H}^{-} / \mathrm{H}^{+} / \mathrm{CO}^{+}$and $\mathrm{O}^{-} / \mathrm{H}^{+} / \mathrm{C}^{+}$channels in $20 \mathrm{~min}$. at the $\mathrm{C} 1 \mathrm{~s} \rightarrow 3 \mathrm{p}$ resonance, these being the highest NIPIPICO count rates registered at the $\mathrm{C} 1 \mathrm{~s}$ edge. The most intense NIPIPICO channel at the $\mathrm{O} 1 \mathrm{~s}$ edge was $\mathrm{O}^{-} / \mathrm{H}^{+} / \mathrm{C}^{+}$ for which we registered the maximum count of about 400 in $20 \mathrm{~min}$. 

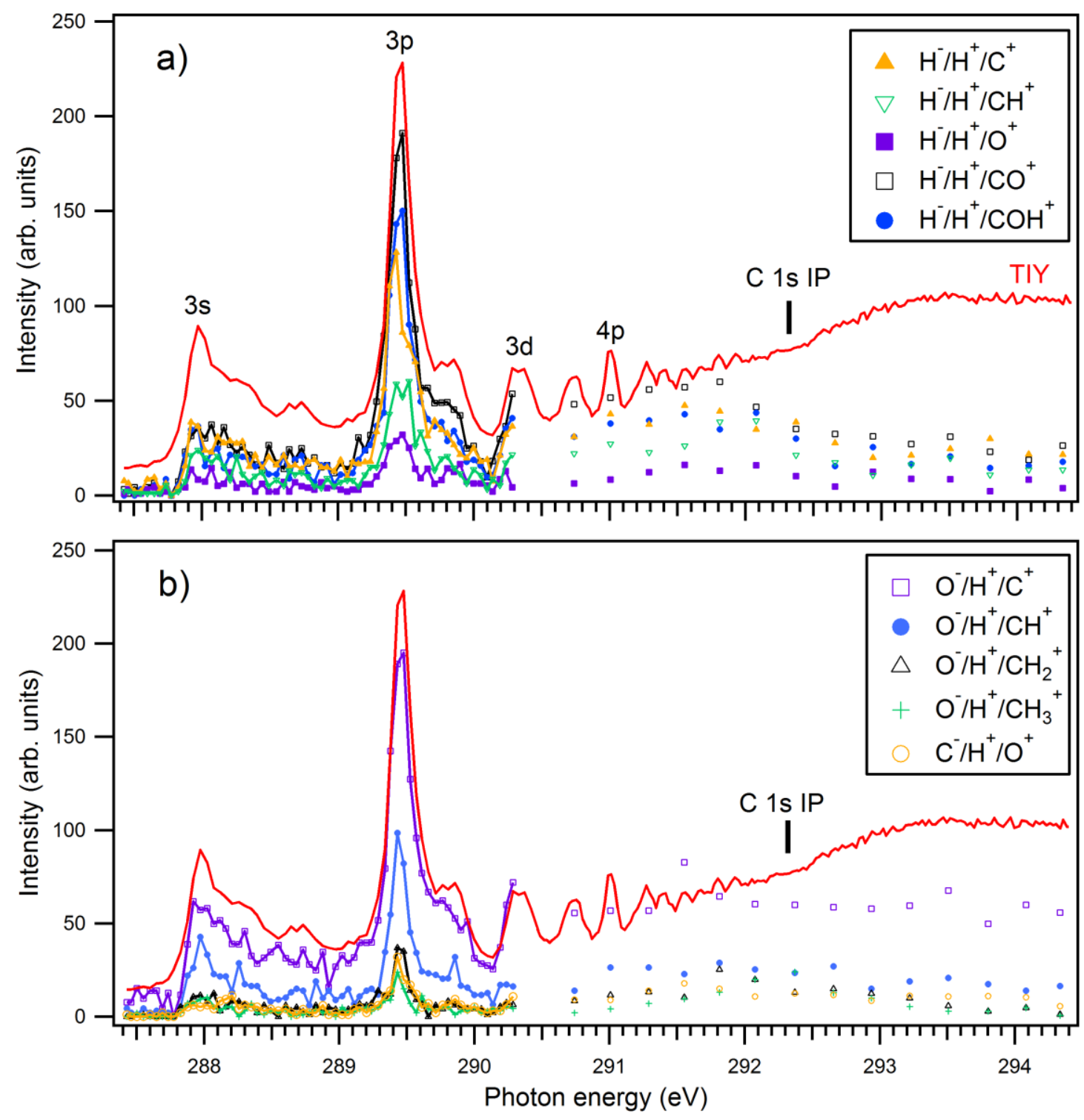

Figure 5. The yields of the most intense NIPIPICO channels at the $\mathrm{C}$ 1s edge of methanol for (a) $\mathrm{NI}^{-} \mathrm{H}^{-}$and (b) $\mathrm{NI}^{-} \mathrm{O}^{-}$and $\mathrm{C}^{-}$. 


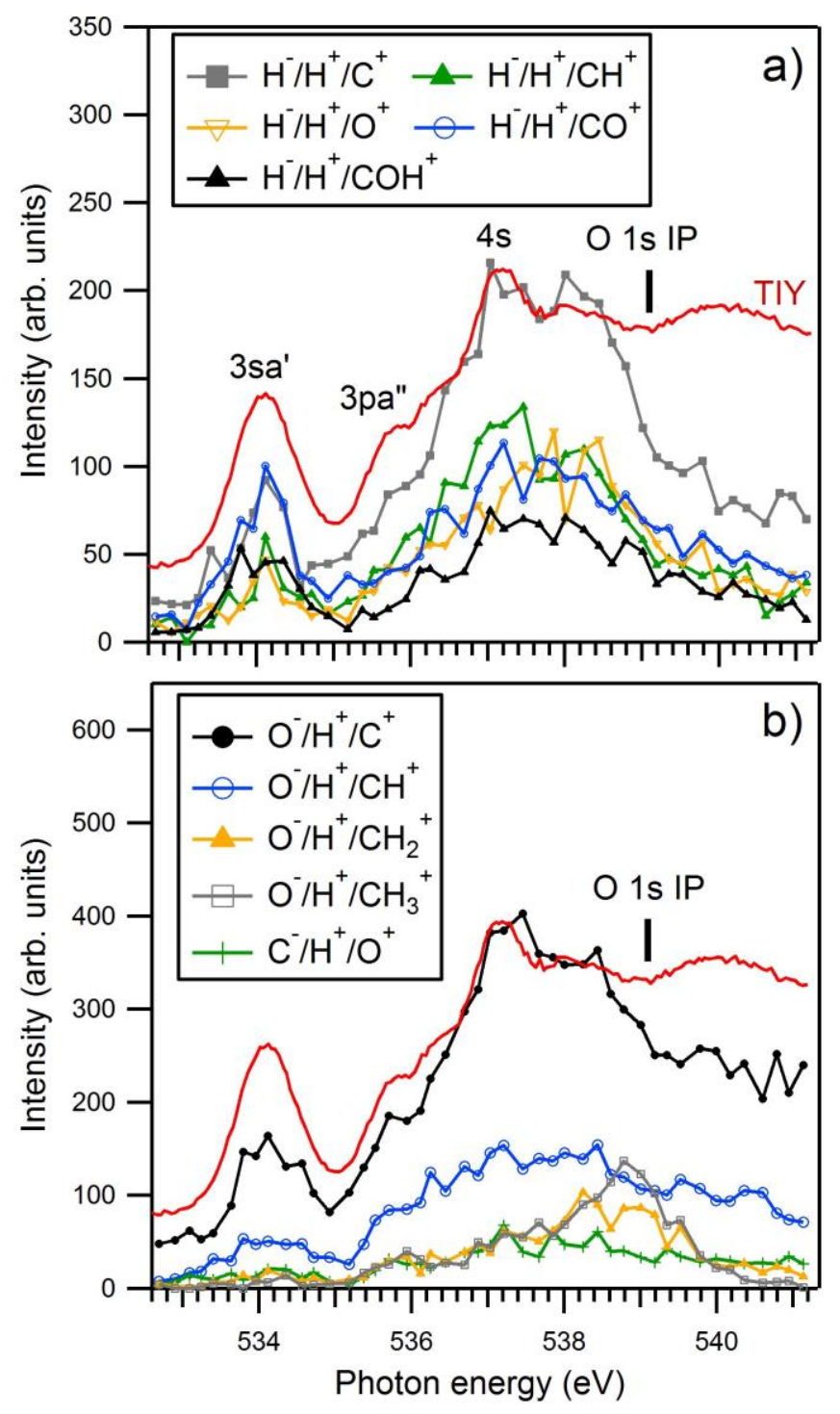

Figure 6. The yields of the most intense NIPIPICO channels at the $\mathrm{O} 1 \mathrm{~s}$ edge of methanol for $(\mathrm{a}) \mathrm{NI}^{-} \mathrm{H}^{-}$and (b) $\mathrm{NI}^{-} \mathrm{O}^{-}$and $\mathrm{C}^{-}$.

At the $C 1$ s edge, all the NIPIPICO channels displayed in Figure 5 show rather similar relative intensities at different $C$ 1s excitations as the TIY does. The NIPIPICO channels also have intensity above the $C$ is IP, where their intensity slowly decreases, except for the $\mathrm{O}^{-} / \mathrm{H}^{+} / \mathrm{C}^{+}$channel which seems to remain strong in the $\mathrm{C}$ 1s continuum. The $\mathrm{C}^{-} / \mathrm{H}^{+} / \mathrm{O}^{+}$channel is among those that lose intensity above the $\mathrm{C} 1 \mathrm{~s}$ threshold, which is opposite to the behavior observed for the $\mathrm{C}^{-} / \mathrm{H}^{+}$channel in Figure $4 \mathrm{a}$ and supports our interpretation that some contamination intensity was included in that NIPICO channel.

At the $O 1$ s edge (Figure 6), different NIPIPICO channels show more varied behaviors than at the $C 1$ s edge. First, the relative intensity of the $\mathrm{H}^{-} / \mathrm{H}^{+} / \mathrm{CO}^{+}$channel is conspicuously high at the $\mathrm{O}$ is $\rightarrow 3$ sa' resonance compared to the other NIPIPICO channels. Secondly, the intensities of the $\mathrm{O}^{-} / \mathrm{H}^{+} / \mathrm{CH}_{2}{ }^{+}$and $\mathrm{O}^{-} / \mathrm{H}^{+} / \mathrm{CH}_{3}{ }^{+}$ channels are very weak at the first resonance ( $\mathrm{O} 1 \mathrm{~s} \rightarrow 3 \mathrm{sa}$ ') but become several times more intense in the 
region of the $\mathrm{O}$ 1s excitations to high Rydberg orbitals. Figure 7 shows the coincidence events in one of the original measurements, performed at the photon energy of $538.8 \mathrm{eV}$ where the $\mathrm{O} / \mathrm{H}^{+} / \mathrm{CH}_{3}{ }^{+}$channel has its maximum. In that channel, all the constituent atoms are detected; the complete dissociation reaction is thus $\mathrm{CH}_{3} \mathrm{OH}^{+} \rightarrow \mathrm{O}^{-}+\mathrm{H}^{+}+\mathrm{CH}_{3}^{+}$.

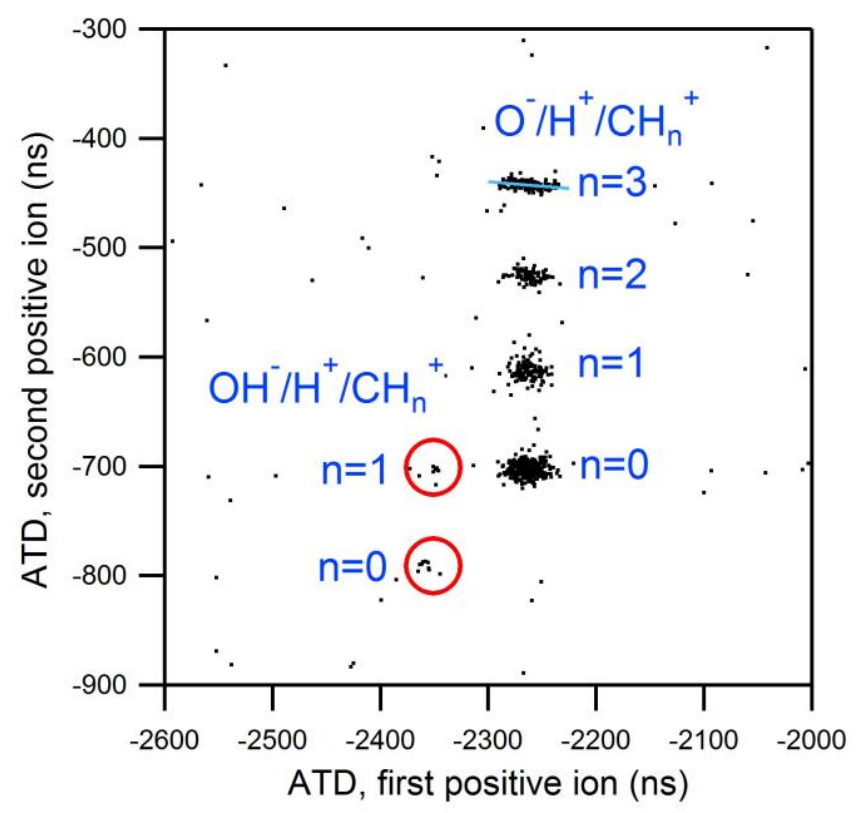

Figure 7. An extract of the NIPIPICO map recorded at the photon energy of $538.8 \mathrm{eV}$, which corresponds to the energy region of the $\mathrm{O} 1 \mathrm{~s}$ excitations to high-Rydberg orbitals. The light-blue line shows the slope of -0.09 fitted to the $\mathrm{O} / \mathrm{H}^{+} / \mathrm{CH}_{3}{ }^{+}$coincidence dots. Red circles denote the positions of the weak $\mathrm{OH}^{-} / \mathrm{H}^{+} / \mathrm{C}^{+}$ and $\mathrm{OH}^{-} / \mathrm{H}^{+} / \mathrm{CH}^{+}$channels. The measuring time was $20 \mathrm{~min}$.

We should remember that parent ions here are mostly formed after spectator resonant Auger transitions, which create two valence holes and leave an electron in a HR orbital (two-hole one-electron states are populated). Although the parent molecule is singly charged, the molecular core has a doubly charged character and is subjected to the Coulombic repulsion. As we observe the $\mathrm{CH}_{3}{ }^{+}$fragment, the parent ion first dissociates as $\mathrm{CH}_{3} \mathrm{OH}^{+} \rightarrow \mathrm{CH}_{3}{ }^{+}+\mathrm{OH}$. The fragments receive equally large but opposite momenta and since their masses are quite similar (15 and $17 \mathrm{amu}$ ), also their kinetic energies will be quite similar. The neutral $\mathrm{OH}$ fragment is likely valence excited; it keeps the electron in a HR orbital and has a hole in a valence orbital. In the second step, $\mathrm{OH}$ dissociates to $\mathrm{O}^{-}+\mathrm{H}^{+}$, whereby $\mathrm{H}^{+}$as a much lighter fragment receives a major part of the available kinetic energy release. This is reflected in the length of the $\mathrm{O}^{-}$ $/ \mathrm{H}^{+} / \mathrm{CH}_{3}{ }^{+}$coincidence pattern along the $x$-axis in Figure 7. (Note that $\mathrm{H}^{+}$is detected before $\mathrm{CH}_{3}{ }^{+}$, so it is the "first" positive ion in Figure 7, even though it is actually created later than $\mathrm{CH}_{3}{ }^{+}$.) If the velocity of the $\mathrm{O}^{-}$ ion after the second dissociation remained the same as the velocity of the $\mathrm{OH}$ fragment before, the $\mathrm{O}^{-}$ $/ \mathrm{H}^{+} / \mathrm{CH}_{3}{ }^{+}$coincidence pattern would be horizontal (slope=0). The observed slope is slightly different, $-0.09 \pm 0.02$. The deviation of the slope from 0 should be caused by the kick that $\mathrm{O}^{-}$receives when $\mathrm{H}^{+}$ departs in the second dissociation. It is also natural to presume that in the other complete fragmentation 
channel, $\mathrm{OH}^{-} / \mathrm{H}^{+} / \mathrm{CH}_{2}{ }^{+}$, the $\mathrm{C}-\mathrm{O}$ bond is broken, $\mathrm{H}^{+}$is detached from the methyl group, and the hydroxyl group as a whole unit becomes negatively charged.

Among the channels involving the $\mathrm{H}^{-}$ion, that of $\mathrm{H}^{-} / \mathrm{H}^{+} / \mathrm{C}^{+}$dominates the $\mathrm{O} 1 \mathrm{~s}$ edge, whereas $\mathrm{H}^{-} / \mathrm{H}^{+} / \mathrm{CO}^{+}$is the most intense one at the $\mathrm{C} 1 \mathrm{~s}$ edge, followed by $\mathrm{H}^{-} / \mathrm{H}^{+} / \mathrm{CHO}^{+}$. Thus, there is some site selectivity in anion production reactions in methanol. These trends do not simply follow the positive ions yields at the core edges. Hempelmann et al. ${ }^{9}$ observed, for instance, that the yield of $\mathrm{HCO}^{+}$is higher than that of $\mathrm{CO}^{+}$at the C 1s edge, which is opposite to the relative intensities of the $\mathrm{H}^{-} / \mathrm{H}^{+} / \mathrm{CO}^{+}$and $\mathrm{H}^{-} / \mathrm{H}^{+} / \mathrm{COH}^{+}$channels. Different positive ion yields show largely different behaviors at the $\mathrm{O} 1 \mathrm{~s}$ edge, ${ }^{9}$ which means that a simple comparison to our results cannot be made.

\section{III.6. NI/PI/PI/PI Coincidence Events}

The experimental data allow us to search for coincidence events where three positive ions were produced together with a negative ion. However, the measuring time of $20 \mathrm{~min}$. per energy point was too short to give clear tracks of such events. Therefore, we have added together the data from several photon energies to improve statistics. This was done for coincidence data collected at 12 photon energies just before the $\mathrm{O}$ 1s IP (i.e., in the region of high Rydberg excitations), and secondly, for 12 photon energies just above the $01 \mathrm{~s} \mathrm{IP.} \mathrm{The} \mathrm{total} \mathrm{measuring} \mathrm{time} \mathrm{was} \mathrm{four} \mathrm{hours.} \mathrm{Figure} \mathrm{8a} \mathrm{shows} \mathrm{the} \mathrm{arrival} \mathrm{time} \mathrm{difference} \mathrm{spectrum}$ of the first ion of only those events where three positive ions were detected in coincidence with a negative particle. We observe that NIPIPIPICO events are most common when the two first ions were $\mathrm{O}^{-} / \mathrm{H}^{+}$and $\mathrm{H}^{-}$ $/ \mathrm{H}^{+}$(the $\mathrm{O}^{-} / \mathrm{C}^{+}$peak obviously arises from false coincidences because there cannot be two slower positive ions than $\mathrm{C}^{+}$when the negative ion is $\left.\mathrm{O}^{-}\right)$. One can determine what the other two ions are by plotting points (ATD of $\mathrm{PI}_{2}, A T D$ of $\mathrm{PI}_{3}$ ) in a two-dimensional coincidence map for a chosen ion pair $\mathrm{NI} / \mathrm{Pl}_{1}$. Figure $8 \mathrm{~b}$ shows such a coincidence map for the case where $\mathrm{NI} / \mathrm{PI}_{1}=\mathrm{H}^{-} / \mathrm{H}^{+}$. The identities of $\mathrm{Pl}_{2}$ and $\mathrm{Pl}_{3}$ can be viewed in Table 1 where we give the ATDs of all the positive ions $\left(\mathrm{Pl}_{1}-\mathrm{Pl}_{3}\right)$ relative to the same negative particle.

The coincidence map of Figure $8 \mathrm{~b}$ reveals several NIPIPICO channels. Particularly interesting is the $\mathrm{H}^{-}$ $/ \mathrm{H}^{+} / \mathrm{C}^{+} / \mathrm{O}^{+}$coincidence contour, which shows hints of being divided in two parts, reflecting the condition that the momenta of the $\mathrm{C}^{+}$and $\mathrm{O}^{+}$ions would be approximately opposite. In this NIPIPIPICO channel, all the ions were different. On its right side, there is another channel that represents four different ions, with $\mathrm{CH}^{+}$replacing $\mathrm{C}^{+}$. Only one of the observed NIPIPIPICO channels includes all the constituent atoms of methanol: $\mathrm{H}^{-} / \mathrm{H}^{+} / \mathrm{H}^{+} / \mathrm{COH}^{+}$. All the detected channels in Figure $8 \mathrm{~b}$ are weak. However, we should recall that the intensities of the channels involving the detection of two protons are underestimated due to the dead time of the MCP detector.

Figure 8a shows that the most abundant $\mathrm{NI} / \mathrm{PI}_{1}$ pair among NIPIPIPICO events is $\mathrm{O}^{-} / \mathrm{H}^{+}$. A similar analysis to Figure $8 \mathrm{~b}$ was done for this ion pair, and it revealed only two NIPIPIPICO channels: $\mathrm{O}^{-} / \mathrm{H}^{+} / \mathrm{H}^{+} / \mathrm{C}^{+}$and $\mathrm{O}^{-}$ $/ \mathrm{H}^{+} / \mathrm{H}^{+} / \mathrm{CH}^{+}$. The former was much more intense and indeed the most intense among all NIPIPIPICO channels. 

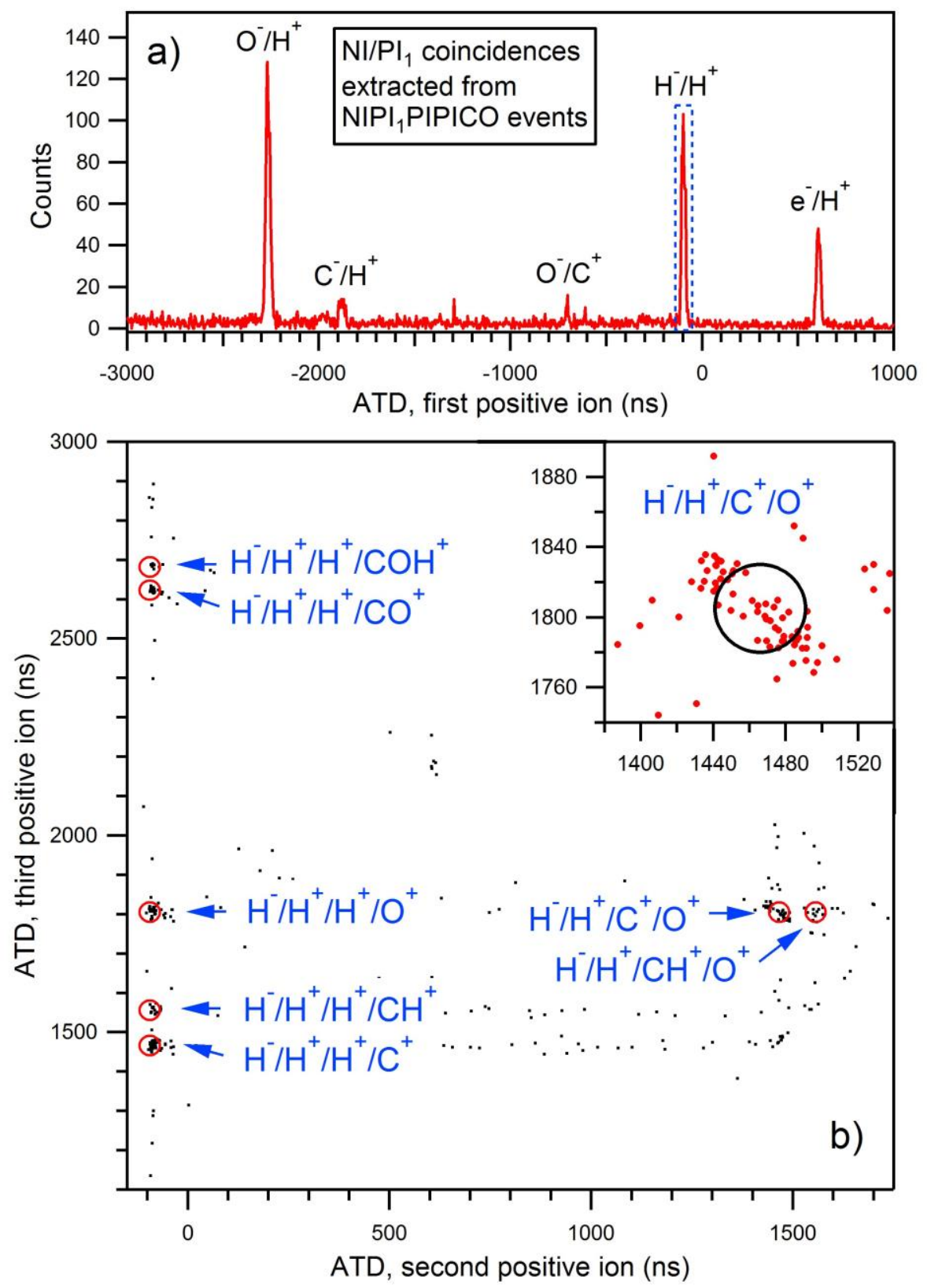

Figure 8. (a) The arrival time difference spectrum of the first positive ion extracted from such events only where three positive ions were detected in coincidence with a negative particle. The data set used comprised 12 measurements recorded at photon energies 536.7-538.8 eV. (b) The coincidence map showing the arrival time difference of the third positive ion vs that of the second positive ion for those events where the NI/PI1 pair has been preselected to be $\mathrm{H}^{-} / \mathrm{H}^{+}$. Red circles indicate the expected positions of the labeled NIPIPIPICO events. The inset shows a magnification of the part containing $\mathrm{H}^{-} / \mathrm{H}^{+} / \mathrm{C}^{+} / \mathrm{O}^{+}$ coincidences. The total measuring time was $4 \mathrm{~h}$. 
NIPIPIPI coincidences were also searched for in the data measured above the $O 1 \mathrm{~s} \mathrm{IP.} \mathrm{We} \mathrm{found} \mathrm{that} \mathrm{the}$ $\mathrm{NI} / \mathrm{PI}_{1}$ ATD spectrum of the NIPIPIPICO events was dominated by the same two peaks as below the $01 \mathrm{~s}$ IP. Their intensities were slightly smaller above the $\mathrm{O} 1 \mathrm{~s}$ threshold, by $20 \%$ for the $\mathrm{O}^{-} / \mathrm{H}^{+}$pair and by $\sim 40 \%$ for the $\mathrm{H}^{-} / \mathrm{H}^{+}$pair. A coincidence map similar to Figure $8 \mathrm{~b}$ displayed four clear NIPIPIPICO channels above the $\mathrm{O}$ 1s threshold $-\mathrm{H}^{-} / \mathrm{H}^{+} / \mathrm{H}^{+} / \mathrm{C}^{+}, \mathrm{H}^{-} / \mathrm{H}^{+} / \mathrm{H}^{+} / \mathrm{O}^{+}, \mathrm{H}^{-} / \mathrm{H}^{+} / \mathrm{H}^{+} / \mathrm{CO}^{+}$and $\mathrm{H}^{-} / \mathrm{H}^{+} / \mathrm{C}^{+} / \mathrm{O}^{+}$- while the statistics were not high enough to tell whether the other channels seen in Figure $8 \mathrm{~b}$ were present or not.

NIPIPIPICO events can occur when doubly charged parent molecules dissociate, which can be presented with a hypothetical four-atomic molecule as $A B C D^{2+} \rightarrow A^{-}+B^{+}+C^{+}+D^{+}$. Normal Auger decay of coreionized states produces doubly charged parent molecules. Most of the final states of Auger decay do not dissociate yielding negative ions, but if some of them do, a four-ion fragmentation is expected to follow. Below the core IP, resonant Auger decay is the most common decay channel. Its basic variations (participator and spectator resonant Auger decay) populate singly positively charged parent molecules, which cannot dissociate through four-ion fragmentation pathways. However, the final states after coreexcitations can be doubly charged if two electrons are emitted simultaneously (resonant double Auger decay) or sequentially (an Auger cascade) in the decay. Negative-ion release from doubly charged molecules could also produce doubly charged fragments (for instance, $A B C D^{++} \rightarrow A^{-}+B^{2+}+C^{+}+D$ ). Such events should be visible in NIPIPICO maps, such as shown in Figures 2 and 3 . However, we did not see any signal at the expected position of the $\mathrm{H}^{-} / \mathrm{H}^{+} / \mathrm{O}^{2+}$ coincidences, which would be expected to be the most likely NIPIPICO channel including a doubly charged ion. This was not surprising, considering that the $\mathrm{H}^{-}$ $/ \mathrm{O}^{2+}$ coincidence peak is extremely weak in Figure 1 . However, the $\mathrm{H}^{-} / \mathrm{O}^{2+}$ peak has a slightly higher relative intensity in the spectra measured above the $01 \mathrm{~s} \mathrm{IP.}$

Double Auger decay of core-inized molecules produces triply charged final states, see e.g. ${ }^{24}$ Intuitively, we assume that the more positive charge a final state has, the less likely it yields a negative ion in dissociation. If a triply charged ion (after double Auger decay) nevertheless dissociated yielding a negative ion, other fragments should carry a total charge of $+4 \mathrm{e}$, likely divided between four singly charged ions. As mentioned above, the detection efficiency of our experiments drops fast with the number of positive ions. We estimate that a statistically significant confirmation or disapproval of the occurrence of coincidence events between one negative ion and four positive ions would have required tens of hours of measuring time. Although detectable in our data, we did not consider such events in the data analysis. No five-body coincidences were observed in the formic acid molecule. ${ }^{15}$

\section{CONCLUSIONS}

The decay of core-excited and core-ionized states of methanol populates final states that can dissociate yielding negative ions. We have studied such fragmentations channels by measuring negative ions in coincidence with positive ions using the experimental setup that consists of two opposite time-of-flight spectrometers. Using a weak magnetic field to deflect unwanted electrons, the instrument can achieve an excellent sensitivity. This is evidenced by the fact that we detected two anions, $\mathrm{C}^{-}$and $\mathrm{CH}^{-}$, which were 
not observed in the previous partial ion yield study of methanol. ${ }^{5}$ The most abundant negative ions are $\mathrm{H}^{-}$ and $\mathrm{O}^{-} \mathrm{OH}^{-}$completes the list.

Our coincidence data revealed about 30 different NIPIPICO channels and nine NIPIPIPICO channels. The most intense NIPIPICO channels belong to the series $\mathrm{O}^{-} / \mathrm{H}^{+} / \mathrm{CH}_{n}{ }^{+}(\mathrm{n}=0-3), \mathrm{H}^{-} / \mathrm{H}^{+} / \mathrm{CH}_{n}{ }^{+}(\mathrm{n}=0-2)$ and $\mathrm{H}^{-}$ $/ \mathrm{H}^{+} / \mathrm{COH}_{n}{ }^{+}(n=0,1)$, where the intensities typically decrease when $n$ increases. As an exception, the $\mathrm{O}^{-}$ $/ \mathrm{H}^{+} / \mathrm{CH}_{3}{ }^{+}$channel gains much intensity at the excitations of $\mathrm{O} 1 \mathrm{~s}$ electrons to high-Rydberg orbitals. The coincidence yields of the NIPIPICO channels at the $\mathrm{C}$ 1s edge mostly follow the shape of the total ion yield curve, while they show more variation at the $O 1$ s edge, being particularly low at the first $O 1$ s excitation ( $\left.01 s \rightarrow 3 s^{\prime}\right)$. The coincidence yields decrease above the core ionization thresholds but do not go to zero (at least not very fast). NIPIPIPI coincidences are much rarer than NIPIPI coincidences, but they do occur. We could not determine their yields because of intensity reasons.

\section{AUTHOR INFORMATION}

\section{Corresponding Author}

*A. Kivimäki, E-mail: antti.kivimaki@maxiv.lu.se. Telephone: +46-70-2638383.

\section{Notes}

The authors declare no competing financial interest.

\section{ACKNOWLEDGMENTS}

The authors acknowledge Elettra-Sincrotrone Trieste for providing beam time (Proposal No. 20150229) and the staff at Elettra for their kind assistance during the experiments.

\section{REFERENCES}

(1) Bambynek, W.; Crasemann, B.; Fink, R.W.; Freund, H.-U.; Mark, H.; Swift, C.D.; Price, R.E.; Rao, P.V. XRay Fluorescence Yields, Auger, and Coster-Kronig Transition Probabilities. Rev. Mod. Phys. 1972, 44, 716813.

(2) Stolte, W.C.; Hansen, D.L.; Piancastelli, M.N.; Dominguez Lopez, L.; Rizvi, A.; Hemmers, O.; Wang, H.; Schlachter, A.S.; Lubell, M.S.; Lindle, D.W. Anionic Photofragmentation of CO: A Selective Probe of CoreLevel Resonances. Phys. Rev. Lett. 2001, 86, 4504-4507.

(3) Ruhl, E.; Flesch, R. Mechanism of Anion Formation in C $1 \mathrm{~s} \rightarrow \pi^{*}$-Excited Carbon Dioxide. J. Chem. Phys. 2004, 121, 5322-5327. 
(4) Stolte, W.C.; Sant'Anna, M.M.; Öhrwall, G.; Dominguez Lopez, I.; Piancastelli, M.N.; Lindle, D.W. Photofragmentation Dynamics of Core-Excitred Water by Anion-Yield Spectroscopy. Phys. Rev. A: At., Mol., Opt. Phys. 2003, 68, 022701.

(5) Stolte, W.C.; Öhrwall, G.; Sant'Anna, M.M.; Dominguez Lopez, I.; Dang, L.T.N.; Piancastelli, M.N.; Lindle, D.W. $100 \%$ Site-Selective Fragmentation in Core-Hole-Photoexcited Methanol by Anion-Yield Spectroscopy. J. Phys. B: At., Mol. Opt. Phys. 2002, 35, L253-L259.

(6) Scully, S.W.J.; Mackie, R.A.; Browning, R.; Dunn, K.F.; Latimer, C.J. Negative Photoion Spectroscopy of $\mathrm{SF}_{6}$ in the Inner Valence and S 2p Energy Regions. J. Phys. B: At., Mol. Opt. Phys. 2002, 35, 2703-2711.

(7) Piancastelli, M.N.; Stolte, W.C.; Guillemin, R.; Wolska, A.; Yu, S.-W.; Sant'Anna, M.M.; Lindle, D.W. Anion and Cation-Yield Spectroscopy of Core-Excited SF 6 . J. Chem. Phys. 2005, 122, 094312.

(8) Eland, J.H.D.; Treves-Brown, B.J. The Fragmentation of Doubly Charged Methanol. Int. J. Mass Spectrom. Ion Processes 1992, 113, 167-176.

(9) Hempelmann, A.; Piancastelli, M.N.; Heiser, F.; Gessner, O.; Rüdel, A.; Becker, U. Resonant Photofragmentation of Methanol at the Carbon and Oxygen K-Edge by High-Resolution lon-Yield Spectroscopy. J. Phys. B: At., Mol. Opt. Phys. 1999, 32, 2677-2689.

(10) Pilling, S.; Boechat-Roberty, H.M.; Santos, A.C.F.; de Souza, G.G.B. Ionic Yield and Dissociation Pathways from Soft X-ray Double-Ionization of Alcohols. J. Electron Spectrosc. Relat. Phenom. 2007, 155, 70-76.

(11) Pilling, S.; Neves, R.; Santos, A.C.F.; Boechat-Roberty, H.M. Photodissociation of Organic Molecules in Star-Forming Regions III. Methanol. Astronomy\&Astrophysics 2007, 464, 393-398.

(12) Nixon, K.L.; Pires, W.A.D.; Neves, R.F.C.; Duque, H.V.; Jones, D.B.; Brunger, M.J.; Lopes, M.C.A. Electron Impact Ionisation and Fragmentation of Methanol and Ethanol. Int. J. Mass. Spectrom. 2016, 404, 48-59.

(13) Stråhlman, C.; Sankari, R.; Kivimäki, A.; Richter, R.; Coreno, M.; Nyholm, R. A Tandem Time-of-Flight Spectrometer for Negative-Ion/Positive-Ion Coincidence Measurements with Soft X-ray Excitation. Rev. Sci. Instrum. 2016, 87, 013109.

(14) Stråhlman, C.; Kivimäki, A.; Richter, R.; Sankari, R. Negative-Ion/Positive-lon Coincidence Yields of Core-Excited Water. J. Phys. Chem. A 2016, 120, 6389-6393.

(15) Stråhlman, C.; Kivimäki, A.; Richter, R.; Sankari, R. Negative- and Positive-lon Fragmentation of CoreExcited Formic-Acid Molecules Studied with Three and Four-Ion Coincidence Spectroscopy, Phys. Rev. A: At., Mol., Opt. Phys. 2017, 96, 023409.

(16) Prince, K. C.; Blyth, R. R.; Delaunay, R.; Zitnik, M.; Krempasky, J.; Slezak, J.; Camilloni, R.; Avaldi, L.; Coreno, M.; Stefani, G.; et al. The Gas-Phase Photoemission Beamline at Elettra. J. Synchrotron Radiat. 1998, 5, 565-568.

(17) Morin, P.; Nenner, I.; Guyion, P.M.; Dutuit, O.; Ito, K. Time of Flight Photoelectron Spectroscopy Using Synchrotron Radiation Study of Resonances in O 2 . J. Chim. Phys. 1980, 77, 605-612.

(18) Prince, K.C.; Richter, R.; de Simone, M.; Alagia, M.; Coreno, M. Near Edge X-ray Absorption Spectra of Some Small Polyatomic Molecules. J. Phys. Chem. A 2003, 107, 1955-1963.

(19) Morin, P.; Nenner, I. Atomic Autoionization Following Very Fast Dissociation of Core-Excited HBr. Phys. Rev. Lett. 1986, 56, 1913-1916. 
(20) Prince, K.C.; Richter, R.; de Simone, M.; Coreno, M. Dynamics of Core Hole States and Ultrafast Dissociation of Organic Molecules. Elettra Highlights 2003-2004 [Online], pp 23-26. https://www.elettra.trieste.it/science/highlights.html (accessed Dec 4, 2017).

(21) Eland, J.H.D. Dynamics of Fragmentation Reactions from Peak Shapes in Multiparticle Coincidence Experiments. Laser Chem. 1991, 11, 259-263.

(22) Hansen, D.L.; Stolte, W.C.; Hemmers, O.; Guillemin, R.; Lindle, D.W. Anion Formation Moderated by Post-Collision Interaction Following Core-Level Photoexcitation of CO. J. Phys. B: At., Mol. Opt. Phys. 2002, 35, L381-L386.

(23) Wilson, K.R.; Cavalleri, M.; Rude, B.S.; Schaller, R.D.; Catalano, T.; Nilssson, A.; Saykally, R.J.; Petterson, L.G.M. X-Ray Absorption Spectroscopy of Liquid Methanol Microjets: Bulk Electronic Structure and Hydrogen Bonding Network. J. Phys. Chem B 2005, 109, 10194-10203.

(24) Eland, J.H.D.; Andric, L.; Linusson, P.; Hedin, L.; Plogmaker, S.; Palaudoux, J.; Penent, F.; Lablanquie P.; Feifel, R. Triple Ionization of $\mathrm{CO}_{2}$ by Valence and Inner Shell Photoionization. J. Chem. Phys. 2011, 135, 134309. 
TOC Graphic

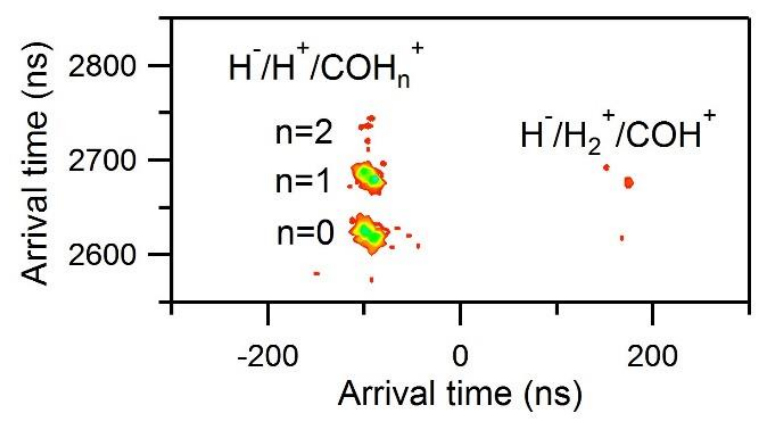

